ORNL/TM-2020/1615

CRADA/ NFE-18-07240

\title{
Binder Jet Printing of H13 Tool Steel
}

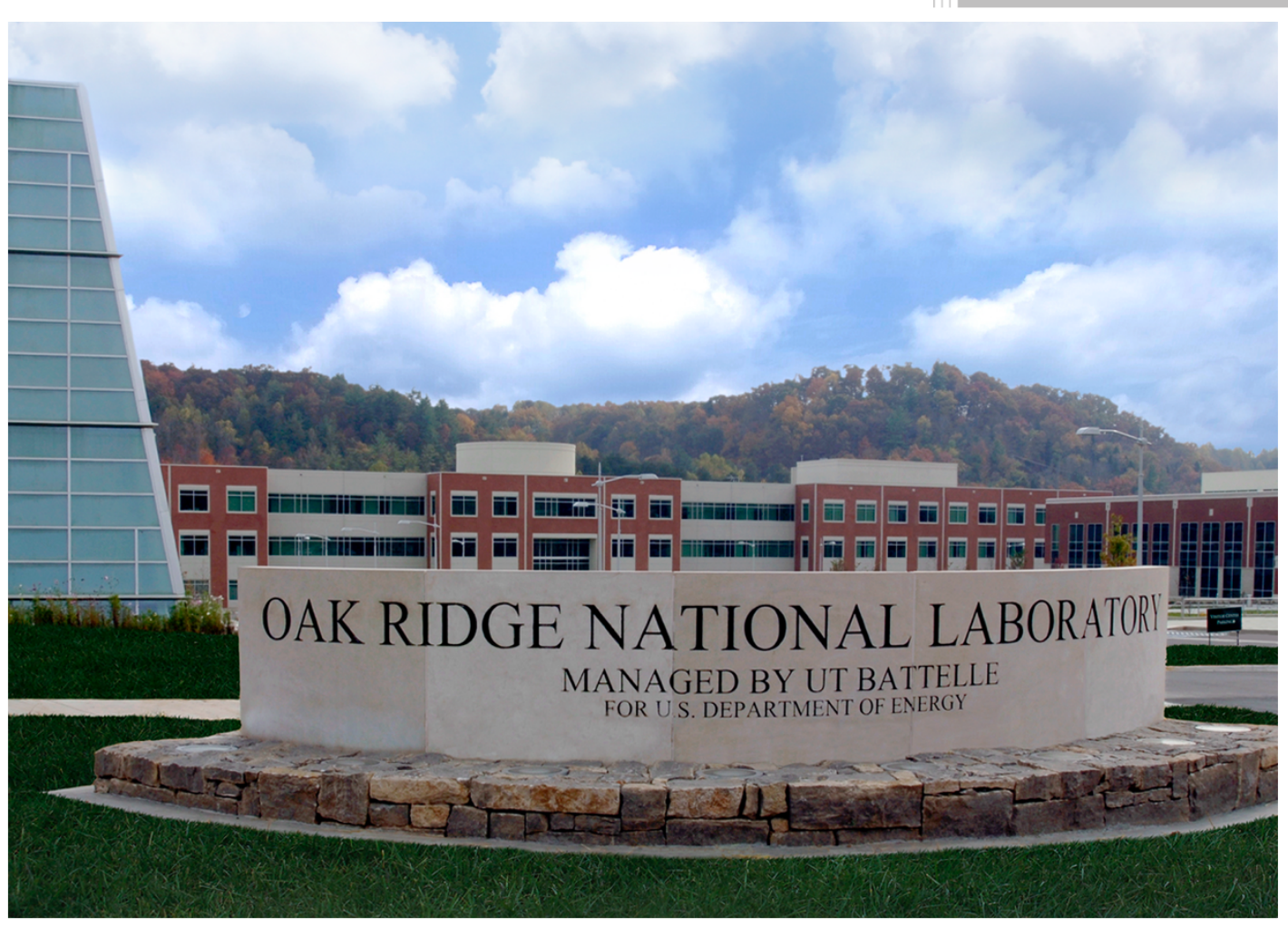

Peeyush Nandwana

April 2020

CRADA FINAL REPORT NFE-18-07240

Approved for Public Release. Distribution is Unlimited. 


\section{DOCUMENT AVAILABILITY}

Reports produced after January 1, 1996, are generally available free via US Department of Energy (DOE) SciTech Connect.

Website http://www.osti.gov/scitech/

Reports produced before January 1, 1996, may be purchased by members of the public from the following source:

National Technical Information Service

5285 Port Royal Road

Springfield, VA 22161

Telephone 703-605-6000 (1-800-553-6847)

TDD 703-487-4639

Fax 703-605-6900

E-mail info@ntis.gov

Website http://www.ntis.gov/help/ordermethods.aspx

Reports are available to DOE employees, DOE contractors, Energy Technology Data Exchange representatives, and International Nuclear Information System representatives from the following source:

Office of Scientific and Technical Information

PO Box 62

Oak Ridge, TN 37831

Telephone 865-576-8401

Fax 865-576-5728

E-mail reports@osti.gov

Website http://www.osti.gov/contact.html

This report was prepared as an account of work sponsored by an agency of the United States Government. Neither the United States Government nor any agency thereof, nor any of their employees, makes any warranty, express or implied, or assumes any legal liability or responsibility for the accuracy, completeness, or usefulness of any information, apparatus, product, or process disclosed, or represents that its use would not infringe privately owned rights. Reference herein to any specific commercial product, process, or service by trade name, trademark, manufacturer, or otherwise, does not necessarily constitute or imply its endorsement, recommendation, or favoring by the United States Government or any agency thereof. The views and opinions of authors expressed herein do not necessarily state or reflect those of the United States Government or any agency thereof. 
Materials Science and Technology Division Advanced Manufacturing Office

\title{
Binder Jet Printing of H13 Tool Steel
}

\author{
Authors \\ Peeyush Nandwana (ORNL) \\ Deserae Goldsby (ORNL) \\ Derek Siddel (ORNL) \\ Rangasayee Kannan (ORNL) \\ James Sears (Carpenter) \\ Date Published: \\ May 2020 \\ Prepared by \\ OAK RIDGE NATIONAL LABORATORY \\ Oak Ridge, Tennessee 37831-6283 \\ managed by \\ UT-BATTELLE, LLC \\ for the \\ US DEPARTMENT OF ENERGY \\ under contract DE-AC05-00OR22725
}

Approved For Public Release 


\section{CONTENTS}

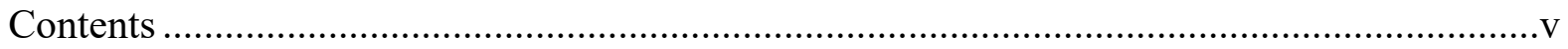

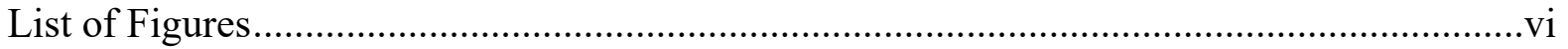

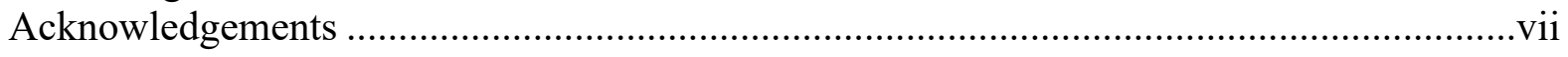

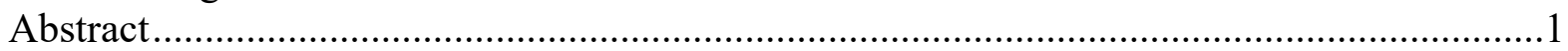

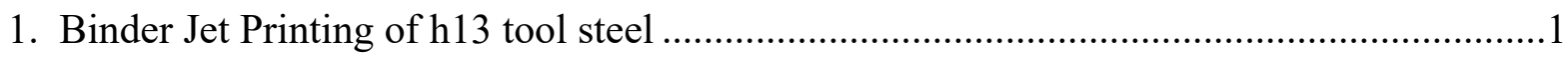

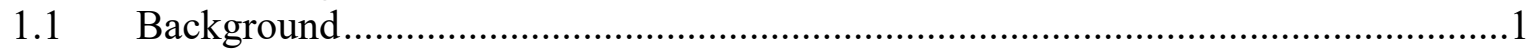

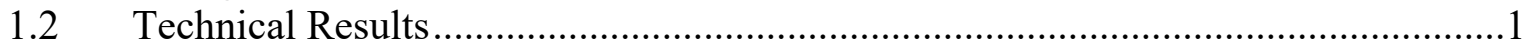

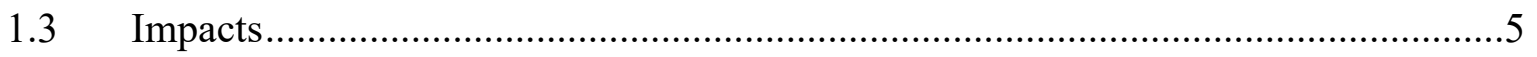

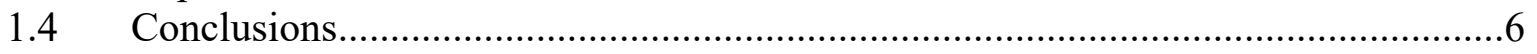

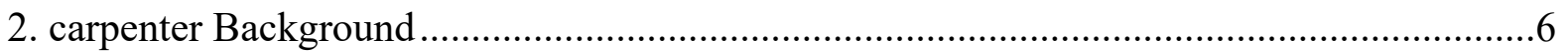




\section{LIST OF FIGURES}

Figure 1 shows the PSD measurements and SEM micrographs for the two powders used for

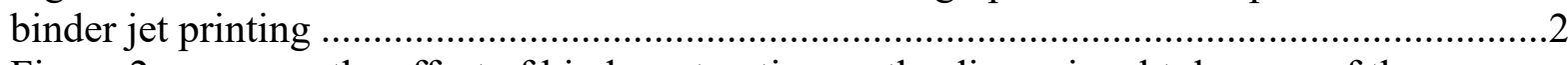
Figure 2 compares the effect of binder saturation on the dimensional tolerance of the green

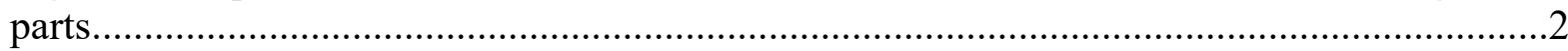
Figure 3 compares the green and brown strengths of the samples fabricated with different binder saturations 3 Figure 4 compares the microstructure of small and large cubes sintered at $1360{ }^{\circ} \mathrm{C}$ and 1380 ${ }^{\circ} \mathrm{C}$.....

Figure 5 shows the hardness maps for cubes 2 and 4 ......................................................

Figure 6 shows the designs that will be potentially be fabricated for determining the feasibility of scaling up binder jet AM H13 for tooling.... 


\section{ACKNOWLEDGEMENTS}

This CRADA NFE-17-06876 was conducted as a Technical Collaboration project within the Oak Ridge National Laboratory (ORNL) Manufacturing Demonstration Facility (MDF) sponsored by the US Department of Energy Advanced Manufacturing Office (CPS Agreement Number 24761). Opportunities for MDF technical collaborations are listed in the announcement "Manufacturing Demonstration Facility Technology Collaborations for US Manufacturers in Advanced Manufacturing and Materials

Technologies" posted at http://web.ornl.gov/sci/manufacturing/docs/FBO-ORNL-MDF-2013-2.pdf. The goal of technical collaborations is to engage industry partners to participate in short-term, collaborative projects within the Manufacturing Demonstration Facility (MDF) to assess applicability and of new energy efficient manufacturing technologies. Research sponsored by the U.S. Department of Energy, Office of Energy Efficiency and Renewable Energy, Advanced Manufacturing Office, under contract DEAC05-00OR22725 with UT-Battelle, LLC. 



\begin{abstract}
ORNL and Carpenter worked on evaluating H13 powders with different powder size distributions for deposition via binder jet additive manufacturing (AM). Binder jet AM has the potential to be a costeffective technique for fabrication of near net shaped tools with complex geometries and internal features such as cooling channels that can improve the production efficiency of injection/compression molding tools. However, a critical challenge in binder jet AM is the densification of the said tool for it to be usable. Powder size distribution can affect the process settings required to deposit the material and the subsequent sintering behavior. In this collaborative effort ORNL and Carpenter demonstrated that the process variables depend on the powder size distribution while the carbon pickup during sintering depends on the binder burnout atmosphere and temperature. On the other hand, there was no noticeable difference in the microstructural evolution of $\mathrm{H} 13$ deposited using the different powder size distributions.
\end{abstract}

\title{
1. BINDER JET PRINTING OF H13 TOOL STEEL
}

This Phase 1 technical collaboration project was started on May 17, 2018 and was completed on March 30, 2020. The collaboration partner Carpenter is a large business. In Phase 1 technical collaboration between ORNL and Carpenter evaluated the H13 powders fabricated by Carpenter for their suitability for binder jet additive manufacturing. H13 is the most commonly used tool steel material for applications ranging from injection/compression molding dies to extrusion and forging dies. Binder jet additive manufacturing can be a potential technique to fabricate these complex dies in a cost-effective manner while introducing features such as internal cooling channels that are challenging to fabricate via conventional manufacturing. However, binder jet AM is sensitive to the powder feedstock being used. Thus, the Phase 1 was focused on understanding the role of powder size distribution on binder jet printing of $\mathrm{H} 13$ tool steel powders for fabricating simpler geometries.

\subsection{BACKGROUND}

Carpenter is a recognized leader in the manufacturing of gas atomized metal powders, with powder metallurgy (PM) experience spanning 50+ years. Carpenter offers nickel and cobalt base alloys, stainless steels, low alloy and maraging steels, and tool steels. While the powders produced by Carpenter are used for a variety of applications, Carpenter is a primary supplier of powders for additive manufacturing (AM) applications, including powder bed, direct fed, binder jet, and wire fed systems.

The ability to employ design advantages of AM for crack prone hot work tool steels will bring significant advantages to the die casting and injection molding industries. For example, use of conformal cooling channels will impart both quality and cost improvements. This project was aimed at demonstrating the features of binder jet technology to the AM market space. Proof concept of binder jet applications will enable the commercialization of AM technologies for alloys that are difficult to fabricate via electron beam or laser fusion owing to their tendency to undergo cracking either during solidification or during solid-state phase transformations. Further, technologies like binder jet AM offer lower-cost alternatives to fusion based technologies, especially with regards to the initial capital investment involved.

\subsection{TECHNICAL RESULTS}

H13 powders with two different powder size distributions (PSD) were chosen for the study with the finer cut being labeled as Powder A and the coarser cut being referred to as Powder B henceforth. The powders were characterized for PSD via a Malvern Morphologi G3 system that relies on calculating PSD based on optical micrographs. Further, scanning electron microscopy (SEM) was conducted on the 
powders to get a better understanding of the powder morphology. Secondary electron micrographs were recorded using a Hitachi TM3030 Plus tabletop scanning electron microscope operating at 5kV. Figure 1 shows the PSD and SEM micrographs for the two powders used in the study

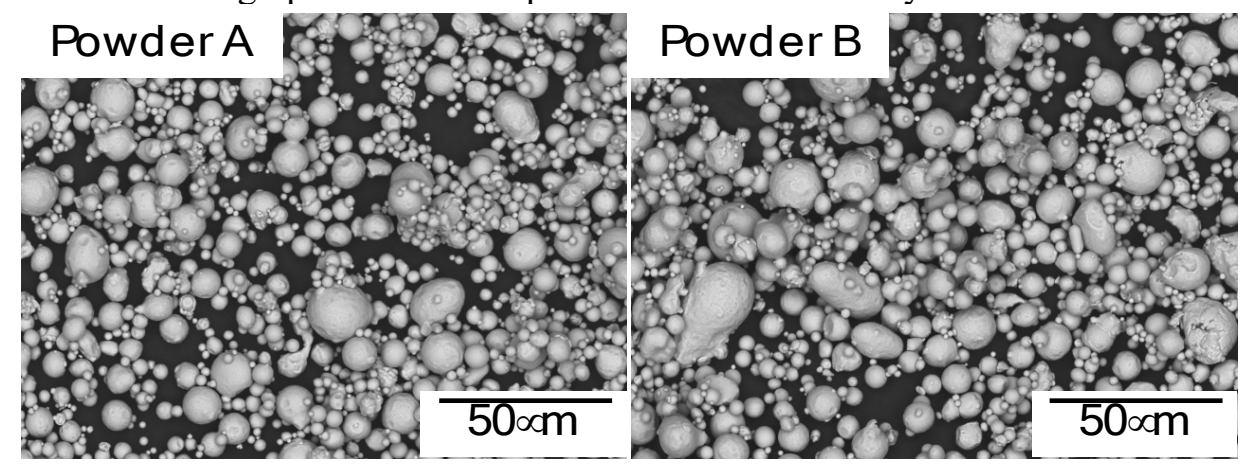

Figure 1 shows the PSD measurements and SEM micrographs for the two powders used for binder jet printing

Based on the PSD measurements the $\mathrm{d}_{10}, \mathrm{~d}_{50}$, and $\mathrm{d}_{90}$ values for the two powders are summarized in Table 1. Based on the SEM micrographs, the powders appear to be mostly spherical with a relatively larger fraction of elongated particles in Powder B compared to Powder A.

\begin{tabular}{|l|l|l|l|l|}
\hline & $\mathrm{d}_{10}$ & $\mathrm{~d}_{50}$ & $\mathrm{~d}_{90}$ & $\mathrm{~d}_{90} / \mathrm{d}_{10}$ \\
\hline Powder A & 7.38 & 11.25 & 16.09 & 2.18 \\
\hline Powder B & 8.44 & 14.85 & 23.89 & 2.83 \\
\hline
\end{tabular}

Table 1 PSD metrics for Powders A and B

The finer powders were used to develop process parameters on an ExOne Innovent retrofitted with a vibratory powder delivery system at ORNL. The samples were deposited at three different binder saturations using a $10 \mathrm{pL}$ printhead and $25 \mu \mathrm{m}$ layer thickness. Figure 2 summarizes the effect of binder saturation on the green part tolerance. It can be seen that the $55 \%$ saturation results in the best tolerance. The results are as expected since increasing saturation can result in impartial binder drying during the printing process thereby resulting in the loss of geometric tolerances. The tolerance can be compensated by possibly increasing the dry time during the deposition process but was beyond the scope of the current work.

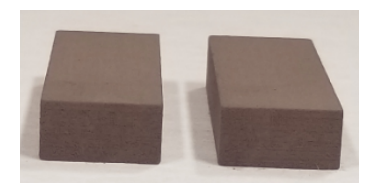

$55 \%$

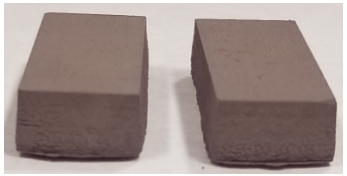

$60 \%$

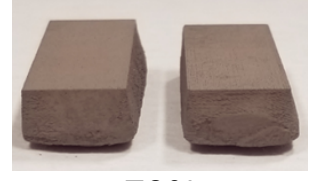

$70 \%$

Figure 2 compares the effect of binder saturation on the dimensional tolerance of the green parts

The green parts were subjected to flexural strength measurements to determine the effect of binder saturation on green strength. Further, binder burnout was conducted on the parts at $630{ }^{\circ} \mathrm{C}$ and 900 ${ }^{\circ} \mathrm{C}$ and flexural strength measurements conducted. The strength of the parts post binder burnout will be referred to as brown strength henceforth. The choice of temperatures was dictated by the fact that $630{ }^{\circ} \mathrm{C}$ is the recommended binder burnout temperature by the original equipment manufacturer (OEM) while $900{ }^{\circ} \mathrm{C}$ was chosen to initiate phase 1 sintering with the aim of maintaining structural integrity post binder burnout. The impact of binder saturation on the green and brown strengths are summarized in Figure 3. An initial glance at the figure points out something counter-intuitive i.e. both the green and brown strengths decrease with increasing binder saturation. Typically, higher saturations result in higher green 
strengths. Between $55 \%$ and $60 \%$ binder saturation the variation in strength is within the scatter band and can be explained by the minimal change in the saturation levels. The reduction in green strength for the sample deposited at $70 \%$ saturation compared to those deposited at $55 \%$ and $60 \%$ is evident. After the binder burnout at the OEM recommended temperature of $630{ }^{\circ} \mathrm{C}$, the flexural strength decreases even below that of the green strength while maintaining a similar trend with regards to the effect of binder saturation. As expected, binder burnout at $900{ }^{\circ} \mathrm{C}$ results in early phases of sintering resulting in significantly higher brown strength compared to the green strength. This Phase 1 sintering would be critical especially for larger parts that may collapse under their own weight or require transfer from furnace to another between binder burnout and final sintering.

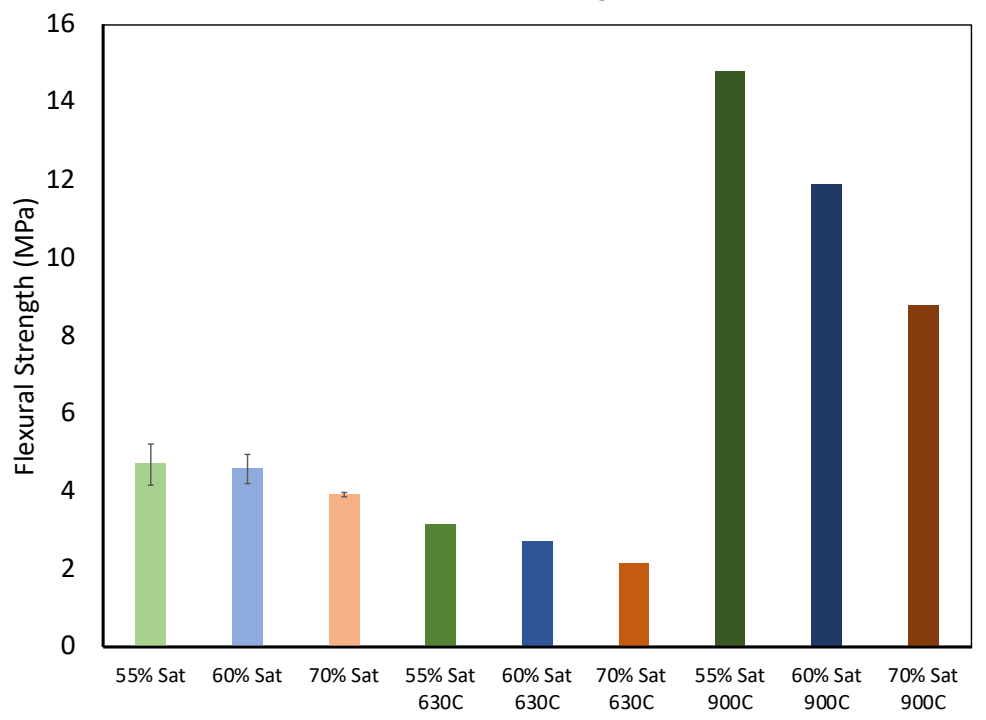

Figure 3 compares the green and brown strengths of the samples fabricated with different binder saturations

Based on the geometric tolerances of the printed green parts, binder saturation level of $55 \%$ was chosen to fabricate samples with different cross sections referred to as small and large coupons henceforth. The samples were ramped at a rate of $10{ }^{\circ} \mathrm{C} / \mathrm{min}$ and subjected to binder burnout at $900{ }^{\circ} \mathrm{C}$ for 5 hours in a vacuum furnace following which they were ramped at $10^{\circ} \mathrm{C} / \mathrm{min}$ to the final sintering temperatures of $1360{ }^{\circ} \mathrm{C}$ and $1380^{\circ} \mathrm{C}$ where they were sintered for 7 and 5 hours respectively. The sample conditions and appropriate designations are summarized in Table 2 . The samples will be referred by their sample designations hereon.

\begin{tabular}{|l|l|l|l|}
\hline Sample Designation & Relative Sample Size & $\begin{array}{l}\text { Sintering Temperature } \\
\text { and Time }\end{array}$ & $\%$ Density \\
\hline Cube 1 & Small Cube & $1360^{\circ} \mathrm{C}$ for 7 hours & 93.5 \\
\hline Cube 2 & Large Cube & $1360^{\circ} \mathrm{C}$ for 7 hours & 92.0 \\
\hline Cube 3 & Small Cube & $1380^{\circ} \mathrm{C}$ for 5 hours & 96.8 \\
\hline Cube 4 & Large Cube & $1380^{\circ} \mathrm{C}$ for 5 hours & 98.9 \\
\hline
\end{tabular}

Table 2 highlights the sample designations, geometries and sintering conditions

Based on the measured density via optical techniques i.e. measuring the porosity volume fraction by image analysis, it is clear that sintering at $1380{ }^{\circ} \mathrm{C}$ for 5 hours results in higher densification compared to sintering at $1360{ }^{\circ} \mathrm{C}$ for both sample geometries. Microstructure examination was conducted on the cubes to reveal the porosity and the underlying microstructure and is summarized in Figure 4. A first glance reveals that sintering at $1380{ }^{\circ} \mathrm{C}$ results in significant coarsening of the microstructure with average grain sizes over $225 \mu \mathrm{m}$ whereas the grain size in the samples sintered at $1360^{\circ} \mathrm{C}$ are closer to $100 \mu \mathrm{m}$. The 
higher porosity in the samples sintered at $1360{ }^{\circ} \mathrm{C}$ is evident at both lower and higher magnification images. On the other hand, the high magnification images show that the samples sintered at $1380{ }^{\circ} \mathrm{C}$ most likely sintered via supersolidus liquid phase sintering (SLPS) owing to the presence of well-defined prior liquid channels. While, there may be a component of SLPS operating in the samples sintered at $1360{ }^{\circ} \mathrm{C}$ as well, based on the micrographs, it appears that the volume fraction was significantly lower.

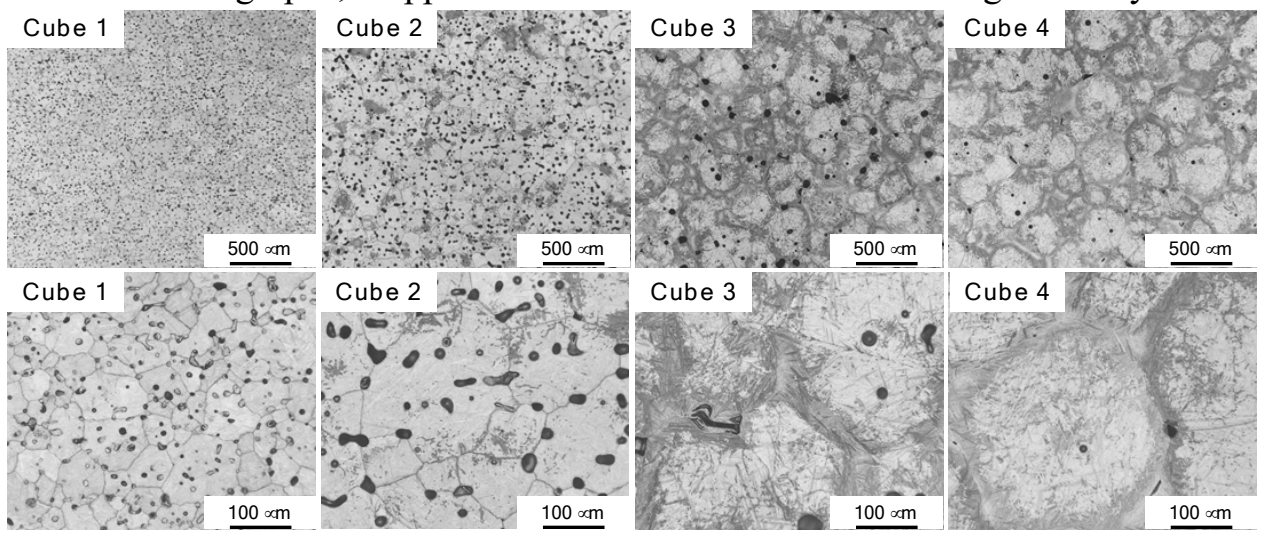

Figure 4 compares the microstructure of small and large cubes sintered at $1360{ }^{\circ} \mathrm{C}$ and $1380{ }^{\circ} \mathrm{C}$

The samples were subjected to chemical analysis to determine whether the sample size and sintering conditions impacted carbon in the material. Carbon was measured using combustion infrared detection per ASTM E 1019-18 while the other elements were measured via direct current plasma emission spectroscopy per ASTM 1097-12. The data was compared to that of as-received powders and is summarized in Table 3.

\begin{tabular}{|l|l|l|l|l|l|}
\hline Element & Powders & Cube 1 & Cube 2 & Cube 3 & Cube 4 \\
\hline Carbon & 0.37 & 0.42 & 0.46 & 0.43 & 0.45 \\
\hline Manganese & 0.38 & 0.40 & 0.40 & 0.40 & 0.39 \\
\hline Silicon & 0.86 & 0.99 & 1.00 & 0.96 & 1.00 \\
\hline Chromium & 4.91 & 5.29 & 5.24 & 5.28 & 5.25 \\
\hline Molybdenum & 1.39 & 1.45 & 1.43 & 1.46 & 1.45 \\
\hline Vanadium & 0.96 & 1.01 & 1.00 & 1.02 & 1.01 \\
\hline Iron & Balance & Balance & Balance & Balance & Balance \\
\hline
\end{tabular}

Table 3 compares the chemistry of the as-received powders with that of the sintered samples for the key elements. Note that the compositions are in weight $\%$.

Based on the data presented in Table 3, the carbon pickup resulting from the binder jet process is quite clear. On the other hand, there is no clear effect of the sintering temperature on carbon retention but there appears to be a geometry effect on carbon retention. Cubes 2 and 4 (large cubes) appear to have slightly higher carbon than the smaller cubes. The reason for this is currently under investigation. It probably maybe a result of the entrapment of the volatile binder burnout product within the sample as the sintering kinetics on the surface are most likely faster than those within due to the temperature gradient resulting from the cross-section and poor thermal conductivity of powders.

Finally, hardness mapping was conducted on the large cubes sintered at $1360{ }^{\circ} \mathrm{C}$ to document the effect of sintering conditions on hardness as well as any variation in hardness as a function of build height. The hardness maps are summarized in Figure 5. it can be seen that Cube 4 has slightly higher hardness than Cube 2. This maybe a combined effect of higher porosity in Cube 2 as well as the nucleation of carbides from prior liquid channels in Cube 4 . However, in either case there is no observable dependence of hardness on the build height and the average hardness $~ 575 \mathrm{HV}$ (57 HRC) in both cases exceeds the requirements of injection molding tools ( $>45 \mathrm{HRC})$. 

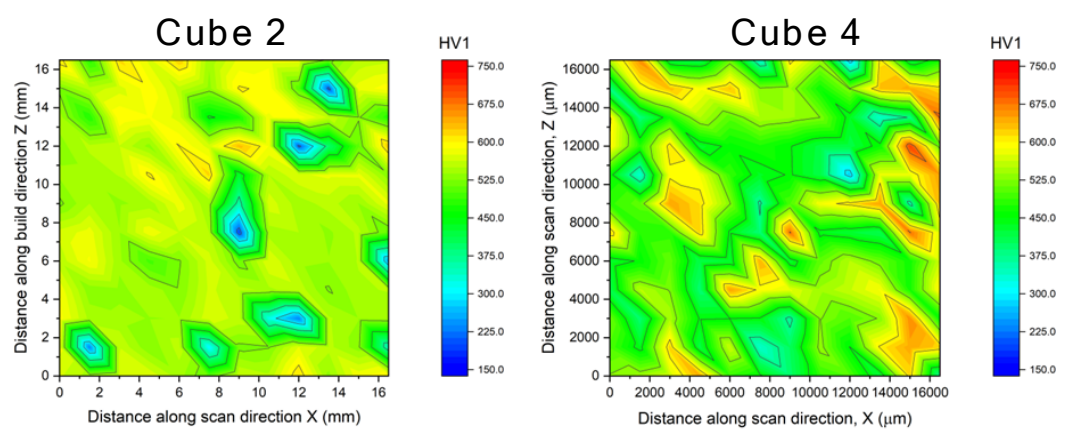

Figure 5 shows the hardness maps for cubes 2 and 4

Two different geometries with conformal cooling channels have been chosen for feasibility studies to scale up binder jet AM of H13 for fabrication of tools and either both or one will be explored contingent on the approval of a Phase 2. The geometries are shown in Figure 6 . To be noted is that the design might change from what is provided below as they are fine-tuned further for specific applications.
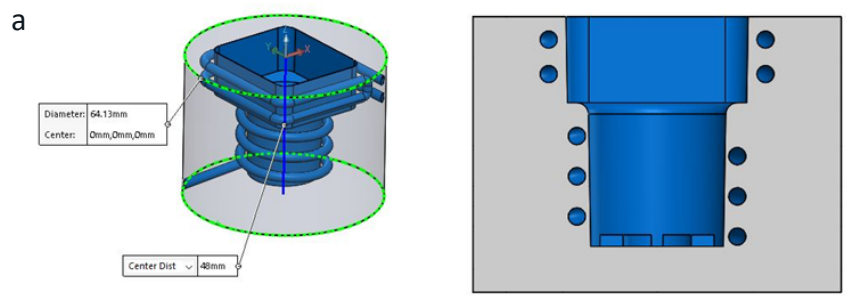

b

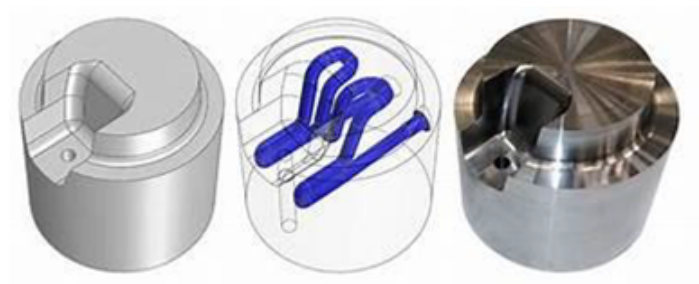

Figure 6 shows the designs that will be potentially be fabricated for determining the feasibility of scaling up binder jet AM H13 for tooling

\subsection{IMPACTS}

This collaboration between ORNL and Carpenter Technologies focused on understanding various aspects of binder jet AM of $\mathrm{H} 13$ tool steel, a material of strategic interest to the tool and die industry. There are currently no studies on the sintering behavior of H13 in the open literature and this study highlights that even with pressureless sintering, densities $>95 \%$ are achievable. Pressureless sintering is critical for binder jet AM since it allows for near full densification of complex geometries and the complexity is not limited by the shape of the sintering can, as is common for metal injection molding. Further, binder jet AM can be utilized to deposit parts at scale not feasible via metal injection molding. We show that conducting binder burnout at elevated temperature increases the strength of the part thereby making it more amenable to be transferred between furnaces by imparting it structural integrity via Stage 1 sintering. The ability to deposit tools with conformal cooling channels can significantly boost productivity, especially for injection molding applications where cooling of the mold accounts for 60$70 \%$ of the cycle time. 


\subsection{CONCLUSIONS}

In summary, ORNL and Carpenter have developed a binder burnout cycle that results in higher part strength post burnout (brown strength) and demonstrated that $\mathrm{H} 13$ can be sintered to $>95 \%$ density via pressureless sintering. It has also been demonstrated that supersolidus liquid phase sintering (SLPS) is the appropriate mechanism to achieve high densification. While SLPS results in microstructure consisting of prior liquid channels and unmelted particles, it exceeds the hardness requirements of injection molding tools. However, the microstructure obtained via SLPS can negatively affect the impact toughness, a critical material property for tooling applications. Further studies will focus on homogenizing the microstructure while increasing the density to near full densification via a combination of hot isostatic pressing (HIP) and heat treatments.

\section{CARPENTER BACKGROUND}

Carpenter is a publicly traded company that is a recognized leader in the manufacturing of gas atomized metal powders, with powder metallurgy (PM) experience spanning 50+ years. Carpenter offers nickel and cobalt base alloys, stainless steels, low alloy and maraging steels, and tool steels. While the powders produced by Carpenter are used for a variety of applications, Carpenter is a primary supplier of powders for additive manufacturing (AM) applications, including powder bed, direct fed, binder jet, and wire fed systems. 